\title{
Ectopic Thyroid in Stomach; a Case Report
}

\author{
Parvin Rajabi $^{1}$, Seyed-Mehdi Eftekhari ${ }^{1}$, Elham Rouhani ${ }^{1}$, Azar Baradaran ${ }^{1 *}$
}

1. Dept. of Pathology, Isfahan University of Medical Sciences, Isfahan, Iran

\begin{tabular}{c}
\hline KEYWORDS \\
Ectopic thyroid \\
Thyroid Dysgenesis \\
Hormonal Dysfunction \\
Stomach \\
\hline Article Info
\end{tabular}

Received 24 Jan 2017;

Accepted 26 Apr 2017;

Published Online 2017;

\begin{abstract}
An ectopic thyroid is a form of thyroid dysgenesis in which an entire or parts of the thyroid gland may be located in another part of the body than what is the usual place. The most frequent location is the base of tongue. Although most cases are asymptomatic, symptoms related to tumor size and its relationship with surrounding tissues, hormonal dysfunction and seldom malignancy may also occur. Any disease affecting the thyroid gland may involve the ectopic thyroid, including malignancy.
\end{abstract}

Corresponding information: Prof. Azar Baradaran MD, Department of Pathology, School of Medicine, Isfahan University of Medical Sciences, Isfahan, Iran. Email: azar.brdrn@gmail.com, Tel: 00989133278027

Copyright $\odot$ 2017, IRANIAN JOURNAL OF PATHOLOGY. This is an open-access article distributed under the terms of the Creative Commons Attribution-noncommercial 4.0 International License which permits copy and redistribute the material just in noncommercial usages, provided the original work is properly cited.

\section{Introduction}

The thyroid gland is the first body endocrine gland to develop and its embryonic development begins during the third or fourth week of gestation. It is composed of two different cell types, the thyroid follicular cells (TFCs) and the C-cells. The TFCs derive from endodermal diverticulum of embryonic mouth cavity in base of the tongue (composed median anlage) and lateral anlages from the bilateral IV branchial pouches, form the lateral thyroid. The initial origin of C-cell precursors is the neural crest. They migrate from the ultimobranchial bodies of the IV pharyngeal pouch. The median anlage descends along as the laryngeal cartilages and hyoid bone and reach in front of the trachea in the 7 th week of gestation.

Ectopic thyroid refers to the presence of thyroid tissue in locations other than the normal anterior neck region between the second and fourth tracheal cartilages. Ectopic thyroid is most common in females. It can be located in midline cervical, lateral cervical, mediastinal and subdiaphragmatic areas. Lingual thyroid, at the region of the foramen cecum, is the most common type (in $90 \%$ of cases). Other sites in the head and neck include trachea, submandibular, lateral cervical regions, palatine tonsils and carotid bifurcation.

More distant location in which ectopic thyroid tissue has been reported include the heart, thymus, esophagus, duodenum, gallbladder and adrenals. However, there are rare reports regarding ectopic thyroid in the stomach. Ectopic thyroid tissues in distant sites could be resulted as aberrant migration or heterotopic differentiation of uncommitted endodermal cells.

In this report, we presented an ectopic thyroid in the stomach and reviewed the pathogenesis, etiology and clinical data of the ectopic thyroid tissue.

\section{Case Report}

A-35-year old male patient presented with gastric pain from six months ago. In endoscopy, fundus and body had normal appearance, diffuse erythema and one erosion in antrum were seen. Therefore, biopsies were taken. In microscopic section, active chronic follicular gastritis with $\mathrm{H}$. Pylori infection and a well-defined nodule of thyroid tissue was seen, composed of follicular cells and colloid material (Figure 1). 


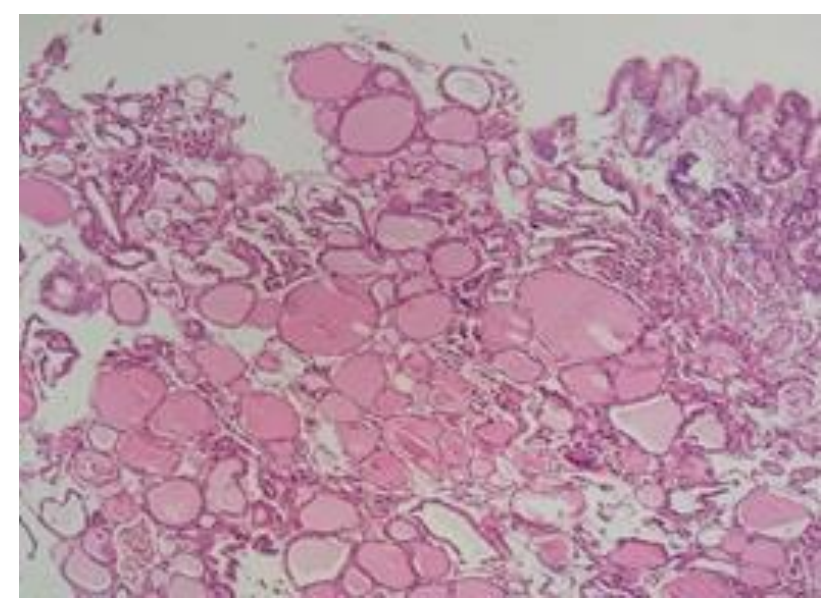

Fig 1. Thyroid nodule composed of follicular cells and colloid (H\&E)

The TFCs was flat and had small size nuclei. Immunohistochemical staining for thyroglobulin (Tg) was performed to confirm follicular thyroid cells (Figure 2).

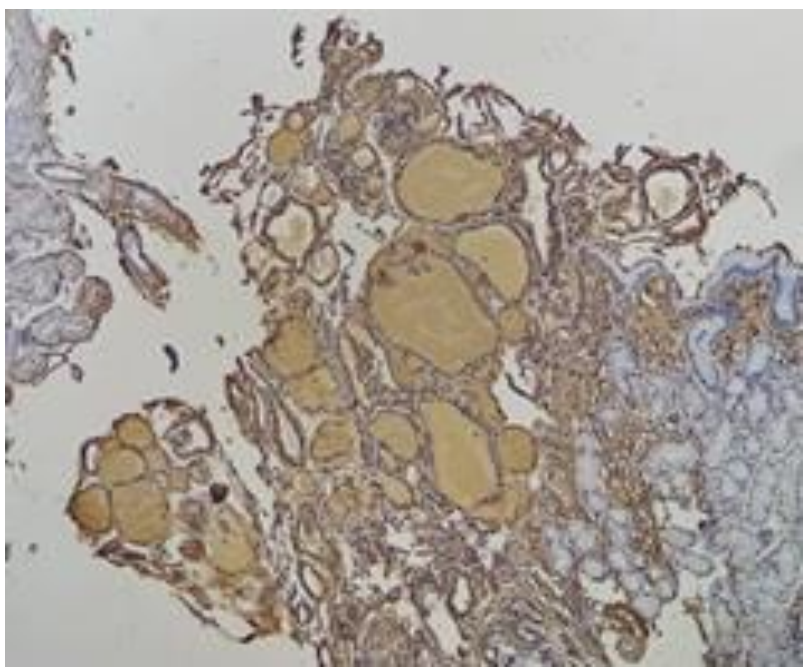

Fig 2. Positive IHC staining for Tg

The patient was euthyroid and had normal thyroid appearance in sonography (no thyroid nodule or suspicious lymph nodes).

\section{Discussion}

There are several theories to elucidate the pathogenesis of ectopic thyroid tissue. It can be from faulty embryogenesis due to failure of migration of thyroid, along the route of thyroglossal duct. These sites are along the thyroglossal line, beginning from the tongue base to the normal gland location. In $70-75 \%$ of cases, lingual thyroid is the only functional thyroid tissue. In most patients with lingual thyroid, hypothyroidism is seen in the absence of orthotropic thyroid. These observations confirm this theory (1).

Until recently, ectopic thyroid tissue in the lateral cervical region was thought to be a metastasis from thyroid carcinoma. However, at now, several cases of benign lateral cervical thyroid have been documented. In this site, when the cells of the lateral anlage do not join to the median, a lateral ectopic thyroid gland is formed. It is usually located in the carotid triangle and submandibular region (2).

An over descent of thyroglossal duct remnants has been suggested as the cause of ectopic thyroid tissue in the mediastinum and perhaps in midsubdiaphragmatic locations. However, ectopic thyroid in the genital tract could be a component of teratoma (through development of germ cells into thyroid tissue). However, in ectopic subdiaphragmatic thyroid gland, heterotopic differentiation of endodermal cells in other organs could be hypothesized. The evidence of normal orthotropic thyroid gland supports this opinion (3).

Clinical findings in ectopic thyroid is variable and most patients are asymptomatic. However, all thyroid disorders (benign or malignant) in orthotropic gland can occur in ectopic tissue. Especially in head and neck and mediastinal sites, ectopic thyroid is commonly detected during periods of increased function of thyroid such as puberty and pregnancy. In this situation goiter can be seen in ectopic tissue. Evident thyroid dysfunction can occur in patients with thyroid ectopy. Hypothyroidism is more frequent and the most common cause of congenital hypothyroidism in infants is ectopic thyroid. Hyperthyroidism is less common and can more be seen in stroma ovary or following stimulation of ectopic tissue by thyroidstimulating immunoglobulins. Ectopic thyroid within the subdiaphragmatic organs is usually and incidental finding on microscopic examination for other causes. However, intra-abdominal thyroid may produce hypertension, hyperthyroidism or low back pain (4).

\section{Conclusion}

It is important, in any case, to rule out a metastatic origin from occult thyroid carcinoma regardless of innocent thyroid cells before a diagnosis of thyroid ectopia is assumed. 


\section{Authors' contribution}

All authors contributed equally to the manuscript.

\section{Conflicts of interest}

There is no conflict of interest that could potentially be construed to affect the material contained in the manuscript submitted to the Journal.

\section{References}

1. Gopal RA, Acharya SV, Bandgar T, Menon PS, Marfatia H, Shah NS. Clinical profile of ectopic thyroid in Asian Indians: a singlecenter experience. Endocrine practice: official journal of the American College of Endocrinology and the American Association of Clinical Endocrinologists. 2009;15(4):322-5.
2. Noussios G, Anagnostis P, Goulis DG, Lappas D, Natsis K. Ectopic thyroid tissue: anatomical, clinical, and surgical implications of a rare entity. European journal of endocrinology. 2011;165(3):375-82.

3. Ibrahim NA, Fadeyibi IO. Ectopic thyroid: etiology, pathology and management. Hormones. 2011;10(4):261-9.

4. Yaghoubi F, Yarmohammadi M, Vasei M. Paraneoplastic proteinuria in papillary renal cell carcinoma; a case report. Journal of renal injury prevention. 2016;5(4):207-9.

\section{How to Cite This Article}

Rajabi P, Eftekhari S, Rouhani E, Mirmosayyeb O, Baradaran, A. Ectopic Thyroid in Stomach; a Case Report. Iran J Pathol, 2018; 13(1): 103-105. 